\title{
Identification of critical residues of influenza neuraminidase in viral particle release
}

\author{
Jennifer R Tisoncik', Ying Guo², Katie S Cordero', Jia Yu ${ }^{3}$, Jianwei Wang ${ }^{4}$, Youjia Cao ${ }^{3}$, Lijun Rong ${ }^{\text {1* }}$
}

\begin{abstract}
Background: Influenza neuraminidase (NA) is essential for virus release from its host cells and it is one of the targets for structure-based antiviral drug design.

Results: In this report, we established a pseudoviral particle release assay to study NA function, which is based on lentiviral particles pseudotyped with influenza glycoproteins HA and NA as a surrogate system. Through an extensive molecular analysis, we sought to characterize important residues governing NA function. We identified five residues of NA, 234, 241, 257, 286 and 345, four of which (except 345) map away from the active site of NA when projected onto the three-dimensional structure of avian influenza H5N1 NA, and substitutions of these residues adversely affected the NA-mediated viral particle release, suggesting that these residues are critical for NA enzymatic activity.

Conclusion: Through extensive chimeric and mutational analyses, we have identified several residues, which map away from the active site and are critical for NA function. These findings provide new insights into NA-mediated pseudoviral particle release and may have important implications in drug design and therapeutics against influenza infection.
\end{abstract}

\section{Background}

Influenza virus causes acute respiratory infections resulting in an estimated 300,000 deaths worldwide each year, of which approximately 36,000 deaths occur in the United States alone. Equally concerning is the emergence of new viral strains in the human population, including the ongoing H5N1 epizootic and swine-origin H1N1 pandemic [1-8]. While influenza vaccines are available, they must be reformulated annually to control for antigenic drift and shift of the two major envelope glycoproteins, hemagglutinin (HA) and neuraminidase (NA). HA binds $\mathrm{N}$-acetyl neuraminic acid (Neu5Ac) mediating virus entry, whereas NA catalyzes Neu5Ac receptor removal facilitating viral particle release. The abundance of Neu5Ac on the cellular surface can impede influenza egress making NA critical for sustained virus infection. NA is one example where an enveloped virus has evolved a mechanism to promote influenza virus release,

\footnotetext{
* Correspondence: lijun@uic.edu

'Department of Microbiology and Immunology, University of Illinois at Chicago, Chicago, IL 60612, USA

Full list of author information is available at the end of the article
}

making optimal influenza virus spread and infection $[9,10]$.

Several other roles have been proposed for NA including (1) clearance of 'decoy' receptors within the respiratory mucin [11], (2) reduction of viral superinfection [12], and (3) enhancement of viral infectivity [13,14]. NA may also enhance viral infectivity by sequestering plasminogen to facilitate activation of HA; however, this function may be virus specific as a recent study involving the 1918 NA does not support this notion [13-15]. It is interesting to note that, in the absence of efficient NA activity, progeny virions aggregate at the cell surface; however, a release-competent mutant lacking the NA active site was the result of decreased HA binding to Neu5Ac receptors. Thus, there appears to exist a balance of NA and HA activities in orchestrating viral particle release [16-18].

NA exists as a tetramer of identical subunits, each monomer containing an active site that is highly conserved across all influenza A and B viruses [19]. In addition to its enzymatic activity, NA has important modifications that have been shown to influence viral infectivity and possibly glycoprotein function [20]. 
For instance, loss of a glycan at position 146 is known to induce neurovirulence in mice $[13,21]$. The NA stalk length has also been demonstrated to be important for enhanced pathogenicity of H5N1 virus [22,23]. Outside of the well characterized active site, few have sought to identify and define important residues of NA. Since NA is one of the two major antigenic glycoproteins of influenza virus, and it is a good target of drug therapeutics, we sought to further characterize the role of NA in this study. Through extensive chimeric and mutational analyses, we have identified several residues, which map away from the active site and are critical for NA function in viral particle release. These findings provide new insights into NA-mediated pseudoviral particle release and may have important implications in drug design and therapeutics against influenza infection.

\section{Results}

\section{Characterization of influenza NA using HIV/HA pseudotype particles}

Reporter-based HIV/HA pseudotyped viruses were generated by co-transfection of HA and env-deficient HIV-1 plasmids into $293 \mathrm{~T}$ producer cells [24]. The human 293T and A549 target cells were challenged with the producer cell culture supernatants collected $48 \mathrm{~h}$ posttransfection and transduction determined by luciferase activity in the target cells. Addition of soluble NA to the culture medium during pseudovirion production enhanced HIV/HA transduction (Figure 1A). Co-transfection of NA from mouse-adapted human virus (PR8), henceforth referred to as $\mathrm{NA}_{\mathrm{H}}$, with the $\mathrm{HA}$ and HIV plasmids resulted in greater transduction efficiency, 1.7 $\times 10^{7}$ and $6.8 \times 10^{6}$ RLU for $293 \mathrm{~T}$ and A549 cells, respectively. In contrast, co-transfection of NA from an avian $\mathrm{H} 5 \mathrm{~N} 1$ virus $\left(\mathrm{NA}_{\mathrm{A}}\right)$ resulted in luciferase levels only slightly higher than the background level, $1.3 \times 10^{3}$ and $1.3 \times 10^{2}$ RLU for $293 \mathrm{~T}$ and A549 cells, respectively (Figure 1A).

A hemagglutination assay was used to further explore the discrepancy between $\mathrm{NA}_{\mathrm{H}}$ and $\mathrm{NA}_{\mathrm{A}}$-mediated pseudovirus production. As shown in Figure 1B, pseudovirions produced in the presence of $\mathrm{NA}_{\mathrm{H}}$ resulted in a hemagglutination titer of $32 \mathrm{HA}$ units $/ \mathrm{ml}$, while expression of $\mathrm{NA}_{\mathrm{A}}$ resulted in no hemagglutination, similar to the PBS control. The supernatants derived from cotransfections with $\mathrm{HIV}$ vector and $\mathrm{NA}_{\mathrm{H}}$ alone, or with HIV vector, $\mathrm{NA}_{\mathrm{H}}$ and VSV-G, the glycoprotein of vesicular stomatitis virus, resulted in no hemagglutination (results not shown). These results correlate with the luciferase data, further suggesting that $\mathrm{NA}_{\mathrm{A}}$ is deficient in mediating pseudovirion release from the $293 \mathrm{~T}$ producer cell surface. To determine if the defect was related to its enzyme activity, NA catalysis of fluorogenic substrate (4-MUNANA) was measured. Compared to $\mathrm{NA}_{\mathrm{H}}$,

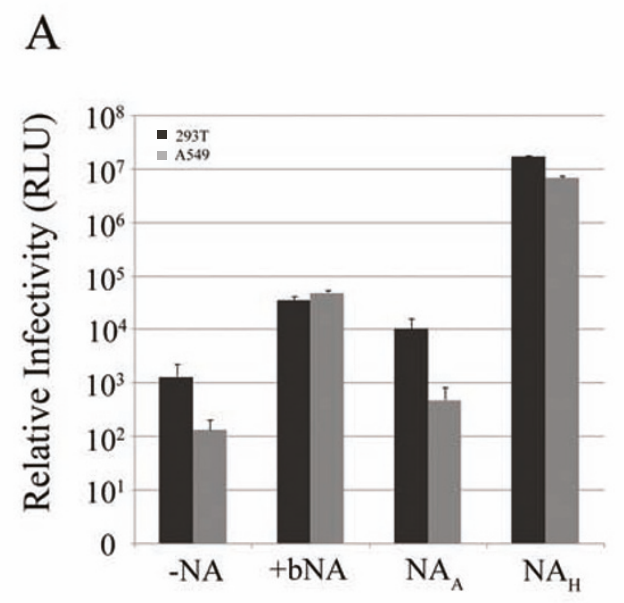

B
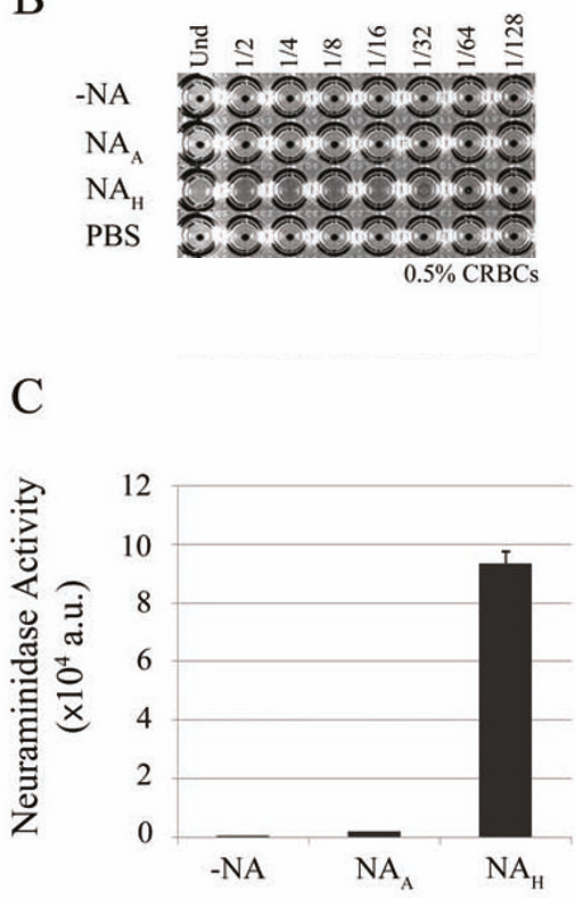

Figure 1 Characterization of HIV/HA pseudoviral particle release mediated by $N A_{A}$ and $N A_{H}$. $A$, relative infectivity of the pseudovirions determined by luciferase activity (relative light units, RLUs) from infected 293T and A549 target cells. Pseudovirions generated in the absence of NA represent background luciferase levels. As a positive control, HA and HIV plasmids were first introduced into 293T producer cells and the transfected cells were then treated with a commercial neuraminidase twice during pseudovirion production (+bNA). Experiments were performed in triplicates and repeated several times. Error bars indicate standard deviations. $B$, hemagglutination activity from titrated $N A_{A}$ and $N A_{H}$ pseudovirion populations mixed with chicken red blood cells. PBS serves as a negative control. $C_{\text {, }}$ neuraminidase activity of $\mathrm{NA}_{\mathrm{A}}$ and $N \mathrm{~N}_{H}$ proteins measured by the release of fluorogenic substrate 4-MUNANA (arbitrary units). Experiments were performed in triplicates and repeated several times, and error bars indicate standard deviations. 
the avian H5N1 NA appears to be defective in its enzymatic activity (Figure $1 C$ ). This may be the result of defective viral genes despite $\mathrm{NA}_{\mathrm{A}}$ being derived from an avian $\mathrm{H} 5 \mathrm{~N} 1$ virus, or through PCR introduced mutations or both. Nevertheless, we reasoned this defective NA clone could allow us to identify critical residues of NA which had not been identified previously.

\section{Functional analysis of $\mathrm{NA}_{\mathrm{H}} / \mathrm{NA}_{\mathrm{A}}$ chimeric constructs}

Comparison of $\mathrm{NA}_{\mathrm{A}}$ and $\mathrm{NA}_{\mathrm{H}}$ primary sequences revealed $83 \%$ amino acid identity with a total of 81 amino acid differences (Figure 2A). All the residues previously identified to be important for NA function are identical for these genes with the exception of position 119. Thus, additional residues of NA likely play an important role in NA activity. To delineate the region(s) critical for NA-mediated pseudovirion release, a panel of six chimeric NA constructs was generated and characterized in the luciferase assay (Figure 2B). Chimeric protein $\mathrm{NA}_{\mathrm{C}}\left(\mathrm{NA}_{\mathrm{A}}\right.$ 176-230) behaved like parental $\mathrm{NA}_{\mathrm{H}}$ resulting in $1.6 \times 10^{7} \mathrm{RLU}$ (Figure $2 \mathrm{~B}$ ). Additionally, hemagglutination and NA enzyme activity of $\mathrm{NA}_{\mathrm{C}}\left(\mathrm{NA}_{\mathrm{A}}\right.$ 176-230) was comparable to $\mathrm{NA}_{\mathrm{H}}$ and consistent with the luciferase data (Table 1). Within this region, aa 176230 , there are five variable residues between the two NAs (Figure 2B), and therefore the differences in this region are not important for NA activity. NA chimeric constructs $\mathrm{NA}_{\mathrm{C}}\left(\mathrm{NA}_{\mathrm{A}}\right.$ 1-230) and $\mathrm{NA}_{\mathrm{C}}\left(\mathrm{NA}_{\mathrm{A}}\right.$ 88-230) displayed reduced luciferase levels and enzyme activity, as well as a complete loss of hemagglutination (Figure $2 \mathrm{~B}$, and Table 1). Similarly, chimeric proteins $\mathrm{NA}_{\mathrm{C}}$ $\left(\mathrm{NA}_{\mathrm{A}} 226-301\right), \mathrm{NA}_{\mathrm{C}}\left(\mathrm{NA}_{\mathrm{A}} 226-362\right)$ and $\mathrm{NA}_{\mathrm{C}}\left(\mathrm{NA}_{\mathrm{A}}\right.$ 226-470) all resulted in a complete loss of NA function. We conclude that variations in the $\mathrm{N}$-terminus of $\mathrm{NA}_{\mathrm{A}}$, aa 88-176, and the C-terminal portion aa226-301 contribute toward the defective $\mathrm{NA}_{\mathrm{H}}$ phenotype (Figure $2 \mathrm{~B}$, Table 1).

To identify the critical residue(s) for NA function, we took a gain-of-function approach and systematically substituted the variable residues within aa regions 88-176 (Table 1) and 226-301 of $\mathrm{NA}_{\mathrm{C}}\left(\mathrm{NA}_{\mathrm{A}} 88-230\right)$ and $\mathrm{NA}_{\mathrm{C}}$ $\left(\mathrm{NA}_{\mathrm{A}}\right.$ 226-301), respectively (Figure $3 \mathrm{~A}$ and Table 1 ). For example, tyrosine 234 in $\mathrm{NA}_{C}\left(\mathrm{NA}_{\mathrm{A}} 226-301\right)$ was substituted to an asparagine $\left(\mathrm{NA}_{\mathrm{C}} \mathrm{Y} 234 \mathrm{~N}\right)$, the existing $\mathrm{NA}_{\mathrm{H}}$ residue corresponding at this position. For $\mathrm{NA}_{\mathrm{C}}$ $\left(\mathrm{NA}_{\mathrm{A}} 226-301\right)$, a total of ten, either single or combined, substitutions were generated (Figure 3A). Three substitutions introduced within $\mathrm{NA}_{\mathrm{C}}\left(\mathrm{NA}_{\mathrm{A}} 226-301\right), \mathrm{Y} 234 \mathrm{~N}$, M257I, and E286K, resulted in increased luciferase activity, hemagglutination and NA enzyme activity, as compared to $\mathrm{NA}_{\mathrm{C}}\left(\mathrm{NA}_{\mathrm{A}}\right.$ 226-301) (Figure 3B-D). Y234N gave $32 \mathrm{HA}$ units $/ \mathrm{ml}$, M257I resulted in $8 \mathrm{HA}$ units $/ \mathrm{ml}$ and HA activity for E286K was observed with the undiluted (Und) sample (Figure $3 \mathrm{C}$ ). These results were generally in agreement with the enzymatic data. However, we did not observe a strong correlation between the magnitude of the HA and the magnitude of the infectivity as measured by the luciferase assay. For example, mutant $\mathrm{Y} 234 \mathrm{~N}$ displayed higher HA activity than E286K (32 vs undiluted), but it gave a lower level of infectivity than that of E286 (also see Table 1). The nature of this discrepancy needs to be further examined in the future.

The $\mathrm{NA}_{\mathrm{C}}\left(\mathrm{NA}_{\mathrm{A}} 226-301\right)$ constructs with $\mathrm{Y} 234 \mathrm{~N}$, M257I, and E286K substitutions resulted in increased levels of NA activity (Figure 3D). Taken together, these results indicate that $\mathrm{N} 234, \mathrm{I} 257$, and $\mathrm{K} 286$ of $\mathrm{NA}_{\mathrm{H}}$ are critical for NA activity and hence function in pseudoviral particle release. Using the same approach, we also demonstrated a critical role of E119 within $\mathrm{NA}_{\mathrm{C}}\left(\mathrm{NA}_{\mathrm{A}}\right.$ 88-230) for enzyme activity (Table 1).

To further examine the potential role of these residues of NA, N234Y, I257M, and K286E substitutions, single or combined, were introduced into $\mathrm{NA}_{\mathrm{H}}$. The single $\mathrm{NA}_{\mathrm{H}}$ substitutions marginally effected NA function. $\mathrm{NA}_{\mathrm{H}}$ double substitution mutants, N234Y/I257M, N234Y/K286E and I257M/K286E, completely abolished NA activity (Figure 4A-C, and Table 1). Interestingly, $\mathrm{NA}_{\mathrm{H}}$ triple substitution mutant resulted in a revertant phenotype. Its enzymatic activity was comparable to $\mathrm{NA}_{\mathrm{H}}$, and it displayed restored luciferase levels and partially restored hemagglutination (Figure 4 and Table 1).

All NA mutants were expressed in the producer cells. $\mathrm{NA}_{\mathrm{H}} \mathrm{N} 234 \mathrm{Y}$ and all three double substitution mutants migrated faster than $\mathrm{NA}_{\mathrm{H}}$ on the SDS-PAGE gel (Figure $4 \mathrm{D}$, left panel). the double substitution NA mutants were not expressed on pseudoviral particles (Figure 4D, right panel). The triple NA mutant showed a similar migration pattern to $\mathrm{NA}_{\mathrm{H}}$ and it was expressed on pseudovirions (Figure 4D, right panel). These data correlated with the $\mathrm{NA}_{\mathrm{H}}$ triple mutant restored activity.

\section{Identification of critical residues for NA function}

An $\mathrm{NA}_{\mathrm{A}}$ variant derived from the $\mathrm{A} /$ chicken/Henan/ 2004 (H5N1) mRNA, henceforth referred to as $\mathrm{NA}_{\mathrm{A}^{*}}$, was generated and displayed an intermediate phenotype in NA function. $\mathrm{NA}_{\mathrm{A}}$ * resulted in a hemagglutination titer of $8 \mathrm{HA}$ units/ml and enhanced enzyme activity compared to $\mathrm{NA}_{\mathrm{A}}$ (Figure $5 \mathrm{~B}$, Table 1). Sequence alignment indicated that $\mathrm{NA}_{\mathrm{A}^{*}}$ contains six amino acid differences from $\mathrm{NA}_{\mathrm{A}}$. Isoleucine at position 8 of $\mathrm{NA}_{\mathrm{A}^{*}}$ is located in the transmembrane domain, and differs from Thr8 of $\mathrm{NA}_{\mathrm{A}}$. The remaining five $\mathrm{NA}_{\mathrm{A}^{*}}$ residues, E119, N234, M241, G248 and G345, which are conserved with $\mathrm{NA}_{\mathrm{H}}$ at the corresponding positions, but differ from that of $\mathrm{NA}_{\mathrm{A}}$ (V119, Y234, R241, W248 and R345) are located in the ectodomain of the protein. 
A

$\begin{array}{ll}\text { NA }_{A} & \text { 1-MNPNQKITTIGSICMVIG IVSIMLQIGNMISIWVSHSIQTGN̈HQAEPISN-----TNFLTEKAVAS } \\ \text { NA }_{H} & \text { 1-MNPNQKIITIGSICLVVGLISLILQIGNISIWISHSIQTGSONHTGICNQNIITYKNSTWVEDTTS }\end{array}$

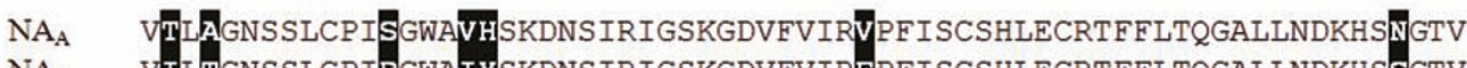
$\mathrm{NA}_{H}$ VILTGNSSLCPIRGWAIYSKDNSIRIGSKGDVFVIREPFISCSHLECRTFFLTQGALLNDKHSSGTV

NA $_{A}$ KDRSPHRTLMSCPVGEAPSPYNSRFESVAWSASACHDGTSWLTIGISGPDNGAVAVLKYNGIITDTI $\mathrm{NA}_{H}$ KDRSPYRALMSCPVGEAPSPYNSRFESVAWSASACHDGMGWLTIGISGPDNGAVAVLKYNGIITETI

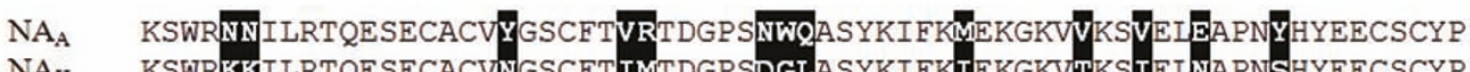
$\mathrm{NA}_{H}$ KSWRKKILRTQESECACVNGSCFTIMTDGPSDGLASYKIFKIEKGKVTKSIEINAPNSHYEECSCYP

NA $_{A}$ DAGEITCVCRDNWHGSNRPWVSFNQNLEYQIGYICSGVFGDNPRPNDGTGSCGPVSPNRAYGVKGFS $\mathrm{NA}_{H} \quad \mathrm{DT} G K V M C V C R D N W H G S N R$ PWVSFDQNLDYQIGYICSGVFGDNPRPEDGTGSCGPVYVDGANGVKGFS

NA A FKYGNVWIGRTKSTNSRSGFEMWDPNGWT ETDSSFSVKEDIVAITDWSGYSGSFVHPELTGLDC $\mathrm{NA}_{H}$ YRYGNGVWIGRTKSHSSRHGFEMIWDPNGWTETDSKFSVRQDVVAMTDWSGYSGSFVQHPELTGLDC

NA $_{\text {A }} \quad$ TRPCFWVELIRGRPKESTIWTS SSSISFCGVNSDTVGWSWPDGAELPFTIDK-449 $\mathrm{NA}_{\mathrm{H}}$ MRPCFWVELIRGRPKEKTIWTSASSISFCGVNSDTVDWSWPDGAELPFSIDK -454

B

$$
\begin{aligned}
& \mathrm{NA}_{\mathrm{A}} \\
& \mathrm{NA}_{\mathrm{H}}
\end{aligned}
$$

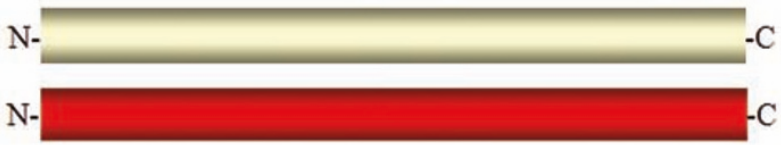

$$
\mathrm{RLU}( \pm \mathrm{SD})
$$$$
1.0( \pm 0.57) \times 10^{4}
$$$$
1.7( \pm 0.03) \times 10^{7}
$$

$\mathrm{NA}_{\mathrm{C}}\left(\mathrm{NA}_{\mathrm{A}}\right.$ 1-230)

$\mathrm{NA}_{\mathrm{C}}\left(\mathrm{NA}_{\mathrm{A}}\right.$ 88-230)

$\mathrm{NA}_{\mathrm{C}}\left(\mathrm{NA}_{\mathrm{A}}\right.$ 176-230)

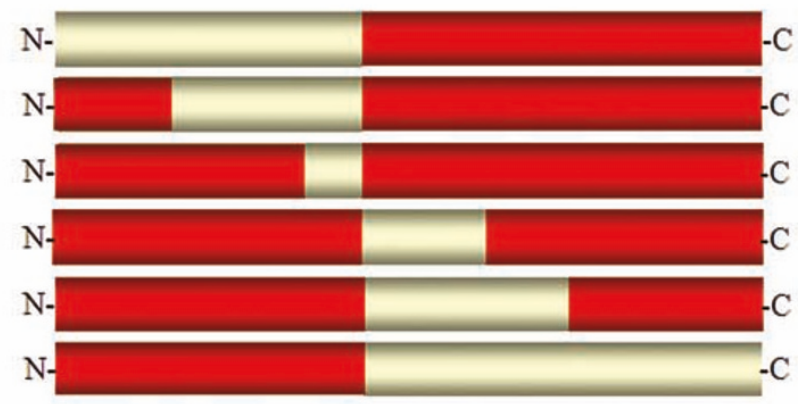

$1.6( \pm 0.39) \times 10^{5}$

$5.0( \pm 0.50) \times 10^{5}$

$1.6( \pm 0.05) \times 10^{7}$

$\mathrm{NA}_{\mathrm{C}}\left(\mathrm{NA}_{\mathrm{A}}\right.$ 226-301)

$\mathrm{NA}_{\mathrm{C}}\left(\mathrm{NA}_{\mathrm{A}}\right.$ 226-362)

$\mathrm{NA}_{\mathrm{C}}\left(\mathrm{NA}_{\mathrm{A}}\right.$ 226-470)

$2.2( \pm 0.22) \times 10^{4}$

$1.1( \pm 0.50) \times 10^{4}$

$1.3( \pm 0.35) \times 10^{4}$

Figure 2 Alignment of $\mathbf{N A}$ and $N A_{H}$ amino acid sequences and schematic of NA constructs. $A$, amino acid sequence alignment of fulllength $N A_{A}$ and $N A_{H}$ proteins. Residue differences are shaded and deletions in the $N A_{H}$ linear sequence are denoted by (-) symbol. $B$, schematic of full-length $N A_{A}$ and $N A_{H}$ proteins and chimeric $N A$ protein panel $\left(N A_{C}\right)$. $N A_{H}$ sequence is colored red and $N A_{A}$ sequence is colored yellow. The $N A_{A}$ regions represented in NA chimeric proteins are labeled according to N2 numbering. The luciferase activities from infected $293 T$ cells are shown on the right. Values are presented as the average of triplicate samples $( \pm S D)$.

To examine the potential roles of these five residues, we first took a gain-of-function approach to determine which amino acid substitutions were required to restore $\mathrm{NA}_{\mathrm{A}}$ function. Since $\mathrm{NA}_{\mathrm{H}}$ substitution mutant $\mathrm{G} 248 \mathrm{~W}$ was comparable to $\mathrm{NA}_{\mathrm{H}}$ (see Table 1), we focused on the following residues of $\mathrm{NA}_{\mathrm{A}}, \mathrm{V} 119, \mathrm{Y} 234, \mathrm{R} 241$ and R345. As shown in Figure 6, all four substitutions in combination were required to restore $\mathrm{NA}_{\mathrm{A}}$ to a level comparable to $\mathrm{NA}_{\mathrm{A}^{*}}$. These results demonstrated that these four residues are critical in maintaining NA activity. 
Table 1 Summary of HIV/HA-mediated relative infectivity and HA and NA activity

\begin{tabular}{|c|c|c|c|c|}
\hline \multirow[t]{2}{*}{ NA construct } & \multicolumn{2}{|c|}{ Luciferase activitya } & \multirow[t]{2}{*}{$\mathrm{HA} \mathrm{U} / \mathrm{ml}$} & \multirow[t]{2}{*}{ 4-MUNANA Release (a.u.) } \\
\hline & 293T cells & A549 cells & & \\
\hline$\overline{N A_{H}}$ & $1.7( \pm 0.03) \times 10^{7}$ & $6.9( \pm 0.5) \times 10^{6}$ & 64 & $9.3( \pm 0.41) \times 10^{4}$ \\
\hline E119V & $8.1( \pm 2.10) \times 10^{5}$ & $1.2( \pm 0.1) \times 10^{3}$ & 0 & $8.3( \pm 0.51) \times 10^{3}$ \\
\hline $\mathrm{N} 234 \mathrm{Y}$ & $1.7( \pm 0.02) \times 10^{6}$ & $4.3( \pm 1.00) \times 10^{5}$ & 16 & $2.5( \pm 0.04) \times 10^{4}$ \\
\hline M241R & $2.7( \pm 0.10) \times 10^{5}$ & $1.6( \pm 1.1) \times 10^{2}$ & 0 & $4.9( \pm 0.16) \times 10^{2}$ \\
\hline G248W & $9.1( \pm 10.3) \times 10^{6}$ & $7.5( \pm 1.7) \times 10^{5}$ & 32 & $2.8( \pm 0.11) \times 10^{4}$ \\
\hline G345R & $3.7( \pm 0.90) \times 10^{4}$ & $1.3( \pm) 0.3 \times 10^{2}$ & 0 & $4.1( \pm 0.25) \times 10^{2}$ \\
\hline $1257 M$ & $1.8( \pm 0.009) \times 10^{7}$ & $4.6( \pm 0.47) \times 10^{6}$ & 64 & $8.3( \pm 0.29) \times 10^{4}$ \\
\hline K286E & $1.4( \pm 0.02) \times 10^{7}$ & $1.5( \pm 0.27) \times 10^{6}$ & 32 & $7.9( \pm 0.38) \times 10^{4}$ \\
\hline N234Y/I257M & $4.1( \pm 1.9) \times 10^{3}$ & $3.5( \pm 4.7) \times 10^{2}$ & 0 & $1.6( \pm 0.24) \times 10^{4}$ \\
\hline N234Y/K286E & $1.6( \pm 0.11) \times 10^{5}$ & $1.1( \pm 0.22) \times 10^{4}$ & 0 & $2.1( \pm 0.32) \times 10^{4}$ \\
\hline I257M/K286E & $9.8( \pm 0.29) \times 10^{3}$ & $1.2( \pm 0.17) \times 10^{4}$ & 0 & $1.0( \pm 0.10) \times 10^{4}$ \\
\hline N234Y/I257M/K286E & $4.3( \pm 0.49) \times 10^{6}$ & $4.7( \pm 0.56) \times 10^{6}$ & 8 & $7.0( \pm 0.37) \times 10^{4}$ \\
\hline$N A_{A^{*}}$ & $6.9( \pm 1.4) \times 10^{5}$ & $6.7( \pm 1.5) \times 10^{5}$ & 2 & $1.7( \pm 0.26) \times 10^{3}$ \\
\hline No NA & $1.3( \pm 0.9) \times 10^{3}$ & $1.3( \pm 0.7) \times 10^{2}$ & 0 & $4.3( \pm 0.1) \times 10^{2}$ \\
\hline$N A_{A}$ & $1.0( \pm 0.57) \times 10^{4}$ & $4.9( \pm 3.4) \times 10^{2}$ & 0 & $6.0( \pm 0.27) \times 10^{2}$ \\
\hline V119E & $5.4( \pm 0.6) \times 10^{3}$ & $7.0( \pm 6.6) \times 10^{2}$ & 0 & $6.7( \pm 0.31) \times 10^{2}$ \\
\hline Y234N & $1.3( \pm 0.2) \times 10^{4}$ & $7.3( \pm 4.9) \times 10^{2}$ & 0 & $4.2( \pm 0.27) \times 10^{2}$ \\
\hline R241M & $1.2( \pm 0.2) \times 10^{4}$ & $9.7( \pm 5.1) \times 10^{2}$ & 0 & $4.4( \pm 0.12) \times 10^{2}$ \\
\hline R345G & $1.3( \pm 0.1) \times 10^{4}$ & $7.8( \pm 2.2) \times 10^{2}$ & 0 & $4.3( \pm 0.42) \times 10^{2}$ \\
\hline V119E/Y234N & $9.1( \pm 2.9) \times 10^{3}$ & $6.9( \pm 3.9) \times 10^{2}$ & 0 & $4.6( \pm 0.14) \times 10^{2}$ \\
\hline V119E/R241M & $1.1( \pm 0.3) \times 10^{4}$ & $5.7( \pm 1.3) \times 10^{2}$ & 0 & $4.0( \pm 0.04) \times 10^{2}$ \\
\hline V119E/R345G & $1.2( \pm 0.1) \times 10^{4}$ & $5.0( \pm 0.6) \times 10^{2}$ & 0 & $4.2( \pm 0.16) \times 10^{2}$ \\
\hline Y234N/R241M & $7.5( \pm 3.0) \times 10^{3}$ & $1.5( \pm 1.0) \times 10^{3}$ & 0 & $4.2( \pm 0.16) \times 10^{2}$ \\
\hline Y234N/R345G & $8.2( \pm 2.8) \times 10^{3}$ & $1.1( \pm 0.9) \times 10^{3}$ & 0 & $4.3( \pm 0.10) \times 10^{2}$ \\
\hline R241M/R345G & $1.8( \pm 0.2) \times 10^{4}$ & $1.7( \pm 0.8) \times 10^{3}$ & 0 & $8.2( \pm 0.47) \times 10^{2}$ \\
\hline V119E/Y234N/R241M & $1.0( \pm 0.05) \times 10^{4}$ & $2.8( \pm 1.2) \times 10^{2}$ & 0 & $4.2( \pm 0.23) \times 10^{2}$ \\
\hline V119E/Y234N/R345G & $1.0( \pm 0.3) \times 10^{4}$ & $3.3( \pm 1.8) \times 10^{2}$ & 0 & $4.4( \pm 0.29) \times 10^{2}$ \\
\hline V119E/R241M/R345G & $2.1( \pm 0.25) \times 10^{5}$ & $1.1( \pm 0.1) \times 10^{4}$ & 0 & $5.4( \pm 0.09) \times 10^{2}$ \\
\hline Y234N/R241M/R345G & ND & ND & ND & ND \\
\hline V119E/Y234N/R241M/R345G & $2.5( \pm 0.6) \times 10^{6}$ & $1.5( \pm 0.1) \times 10^{6}$ & 2 & $2.7( \pm 0.99) \times 10^{3}$ \\
\hline$N A_{C}\left(N A_{A} 176-230\right)$ & $1.6( \pm 0.05) \times 10^{7}$ & $3.0( \pm 0.57) \times 10^{6}$ & 64 & $5.5( \pm 0.08) \times 10^{4}$ \\
\hline$N A_{C}\left(N A_{A} 88-230\right)$ & $5.0( \pm 0.50) \times 10^{5}$ & $1.9( \pm 0.58) \times 10^{4}$ & 0 & $2.3( \pm 0.07) \times 10^{4}$ \\
\hline$N A_{C}\left(N A_{A} 1-230\right)$ & $1.6( \pm 0.39) \times 10^{5}$ & $6.8( \pm 2.1) \times 10^{3}$ & 0 & $4.5( \pm 0.10) \times 10^{3}$ \\
\hline S95R & $4.3( \pm 0.07) \times 10^{5}$ & $1.9( \pm 0.5) \times 10^{4}$ & 0 & $2.1( \pm 0.12) \times 10^{4}$ \\
\hline V99l/H100Y & $5.9( \pm 0.6) \times 10^{5}$ & $2.6( \pm 0.1) \times 10^{4}$ & 0 & $3.1( \pm 0.03) \times 10^{4}$ \\
\hline V119E & $1.4( \pm 0.08) \times 10^{7}$ & $2.1( \pm 0.1) \times 10^{6}$ & 16 & $3.0( \pm 0.09) \times 10^{4}$ \\
\hline N146S & $1.5( \pm 0.2) \times 10^{5}$ & $7.0( \pm 1.5) \times 10^{3}$ & 0 & $1.1( \pm 0.02) \times 10^{4}$ \\
\hline H155Y/T157A & $3.8( \pm 0.8) \times 10^{5}$ & $2.4( \pm 0.3) \times 10^{4}$ & 0 & $2.0( \pm 0.06) \times 10^{4}$ \\
\hline$N A_{C}\left(N A_{A} 226-470\right)$ & $1.3( \pm 0.35) \times 10^{4}$ & $1.1( \pm 0.5) \times 10^{3}$ & 0 & $4.0( \pm 0.09) \times 10^{2}$ \\
\hline$N A_{C}\left(N A_{A} 226-362\right)$ & $1.1( \pm 0.50) \times 10^{4}$ & $1.4( \pm 0.5) \times 10^{4}$ & 0 & $4.3( \pm 0.02) \times 10^{2}$ \\
\hline$N A_{C}\left(N A_{A} 226-301\right)$ & $1.2( \pm 0.09) \times 10^{5}$ & $2.5( \pm 0.7) \times 10^{3}$ & 0 & $1.3( \pm 0.02) \times 10^{3}$ \\
\hline Y234N & $7.2( \pm 0.56) \times 10^{6}$ & $3.6( \pm 0.3) \times 10^{5}$ & 32 & $1.5( \pm 0.04) \times 10^{4}$ \\
\hline N247D/W248G/Q249L & $1.0( \pm 0.31) \times 10^{6}$ & $6.2( \pm 2.6) \times 10^{3}$ & 0 & $1.5( \pm 0.09) \times 10^{3}$ \\
\hline M257l & $7.1( \pm 1.37) \times 10^{6}$ & $6.0( \pm 1.0) \times 10^{4}$ & 4 & $1.2( \pm 0.01) \times 10^{4}$ \\
\hline V263T/N266l & $6.5( \pm 0.80) \times 10^{4}$ & $1.1( \pm 0.6) \times 10^{3}$ & 0 & $4.8( \pm 0.37) \times 10^{2}$ \\
\hline E269N & $2.5( \pm 0.52) \times 10^{5}$ & $6.4( \pm 3.0) \times 10^{3}$ & 0 & $1.1( \pm 0.07) \times 10^{3}$ \\
\hline
\end{tabular}


Table 1 Summary of HIV/HA-mediated relative infectivity and HA and NA activity (Continued)

\begin{tabular}{lcccc}
\hline Y273S & $1.2( \pm 0.07) \times 10^{5}$ & $2.9( \pm 0.6) \times 10^{3}$ & 0 & $5.0( \pm 0.26) \times 10^{2}$ \\
A284T & $1.0( \pm 0.08) \times 10^{5}$ & $2.6( \pm 1.0) \times 10^{3}$ & 0 & $6.2( \pm 0.15) \times 10^{2}$ \\
E286K & $1.8( \pm 0.004) \times 10^{7}$ & $2.2( \pm 0.1) \times 10^{6}$ & Und & $1.6( \pm 0.04) \times 10^{4}$ \\
I287V & $6.1( \pm 0.45) \times 10^{5}$ & $1.2( \pm 0.1) \times 10^{4}$ & 0 & $1.2( \pm 0.01) \times 10^{3}$ \\
T288M & $1.6( \pm 0.06) \times 10^{6}$ & $6.0( \pm 0.3) \times 10^{4}$ & 0 & $5.2( \pm 0.18) \times 10^{3}$ \\
\hline
\end{tabular}

${ }^{\alpha}$ All values are in relative light units (RLU). Standard errors of the means are in parentheses.

ND, not determined

Und, undiluted

Second, a loss-of-function approach was used to determine which amino acid substitutions adversely affected the function of $\mathrm{NA}_{\mathrm{H}}$. Substitutions E119V, M241R and G345R abolished $\mathrm{NA}_{\mathrm{H}}$ activity whereas substitution $\mathrm{N} 234 \mathrm{Y}$ resulted in a moderate reduction in NA enzyme activity and luciferase levels from target cells. In contrast, substitution G248W did not adversely affect the NA-mediated HIV pseudovirus release (Figure 6A and $6 \mathrm{C}$, and Table 1 ). In general, these results were consistent with that of the HA assay (Figure 6B and Table 1). $\mathrm{NA}_{\mathrm{H}}$ substitution mutants M241R, G345R and E119V resulted in no hemagglutinating virions, while the HA titer of $\mathrm{NA}_{\mathrm{H}} \mathrm{G} 248 \mathrm{~W}$ was comparable to parental $\mathrm{NA}_{\mathrm{H}}$ and $\mathrm{NA}_{\mathrm{H}} \mathrm{N} 234 \mathrm{Y}$ resulted in $16 \mathrm{HA}$ units $/ \mathrm{ml}$. Thus, these results indicate that two additional residues (M241 and G345) are also critical for $\mathrm{NA}_{\mathrm{H}}$ activity. All NA mutants were expressed in producer cell lysates and in pseudovirion lysates with the exception of $\mathrm{NA}_{\mathrm{H}}$ mutants, M241R and G345R (Figure 6D). To ensure that the mutations did not adversely affect NA folding or transport, we evaluated NA cellular surface expression using a biotinylation assay. It was found that $\mathrm{NA}_{\mathrm{H}}$ single and combined substitutions did not disrupt the capacity for NA to be properly folded and transported to the plasma membrane. All NA mutants in this panel were detected on the surface and showed comparable expression levels (data not shown). Hence, the defective NA function observed with $\mathrm{NA}_{\mathrm{H}}$ double substitution mutants and $\mathrm{NA}_{\mathrm{H}} \mathrm{M} 241 \mathrm{R}$ and G345R single mutants is not a result of reduced cell surface expression levels.

\section{Discussion}

In this study, we sought to identify important residues for influenza virus NA function. Previous reports have identified numerous critical residues forming the NA enzyme active site and surrounding framework (in N2 numbering): Arg 118, Glu 119, Asp 151, Arg 152, Asp 198, Ile 222, Arg 224, Glu 227, Asp 243, His 274, Glu 276, Glu 277, Arg 292, and Asp 330, Arg 371 $[19,25-28]$. The goal of the current work was to further examine and identify additional critical residues of NA using an established pseudotyping system to study influenza virus envelope glycoprotein function [24]. We demonstrated HIV/HA pseudovirion production may be used as a suitable surrogate system to indirectly measure viral particle release from $293 \mathrm{~T}$ producer cells. Through an extensive molecular analysis, we identified and characterized critical molecular determinants at the following five positions: 234, 241, 257, 286 and 345 In mapping these positions onto the three-dimensional structure of avian H5N1 NA, we found that these residues, with the exception of G345, are distal to the active site (Figure 7). Internal residues, M241 and M257, are part of $\beta$-sheet 3 , while residues 234 and 286 are surface exposed and localize more closely together on the ectodomain surface proximal to the virion membrane. G345 is part of an antigenic site (aa 339-347) located on the rim of the enzyme pocket. Sequence alignment of over 8,000 NAs revealed greatest amino acid variability at positions 257 and 286 and to a lesser extent at position 234. In contrast, M241 and G345 are highly conserved with a very low frequency of amino acid variations observed at these two positions.

This study was initiated when it was observed that two NA genes demonstrated distinct phenotypes. An NA gene derived from mouse-adapted PR8 influenza virus $\left(\mathrm{NA}_{\mathrm{H}}\right)$ could efficiently facilitate release of $\mathrm{HIV} /$ HA pseudovirions from the producer cells, whereas an avian $\mathrm{H} 5 \mathrm{~N} 1 \mathrm{NA}$ clone $\left(\mathrm{NA}_{\mathrm{A}}\right)$ was completely defective. By creating a panel of chimeric constructs between these two genes, we were able to identify two regions of NA, aa regions 88-176 and 226-301, likely responsible for the functional difference of these two NAs (see Figure 2). Mutational analysis of these regions led to identification of critical molecular determinants at positions 234, 257 and 286. We also identified residues 241 and 345 , and further confirmed the importance of residue 234 by restoring $\mathrm{NA}_{\mathrm{A}}$ activity. Introduction of arginine at either position 241 or 345 completely abrogated NA function; however, $\mathrm{NA}_{\mathrm{H}} \mathrm{M} 241 \mathrm{R}$ and G345R mutants were detected on the cells surface through biotinylation. Hence, the defective NA function observed with $\mathrm{NA}_{\mathrm{H}}$ M241R and G345R single mutants is not a result of reduced expression on the cell surface.

Viral envelope modifications, including glycosylation patterns, may dictate, in part, viral glycoprotein function. 
A

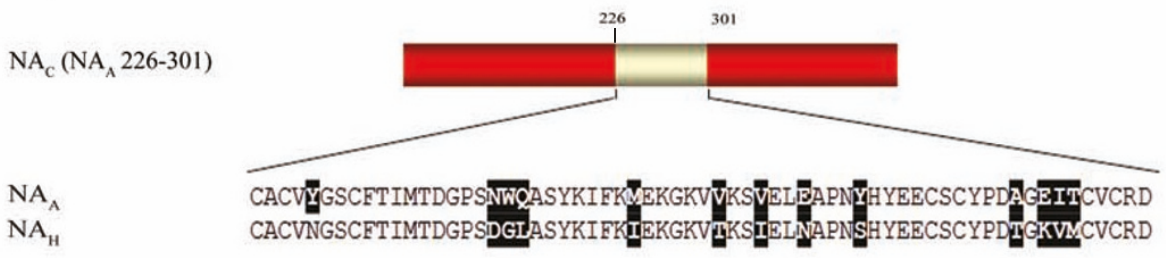

B

(886)

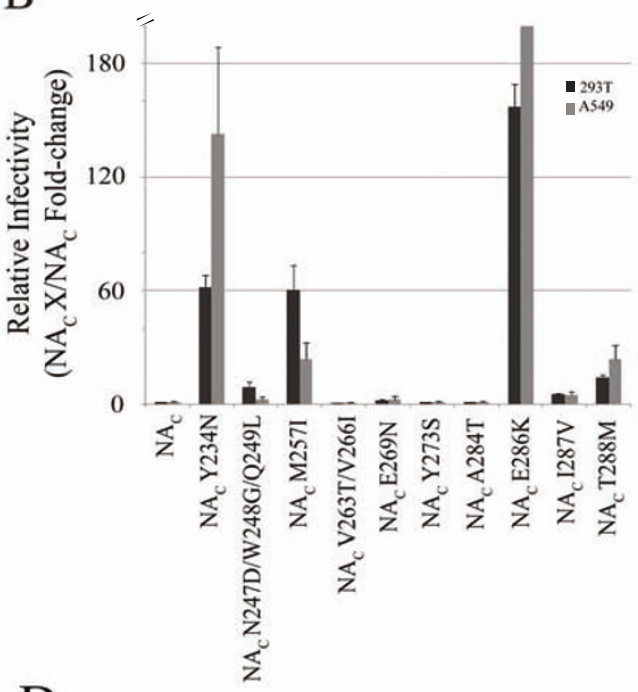

C

$\mathrm{D}$
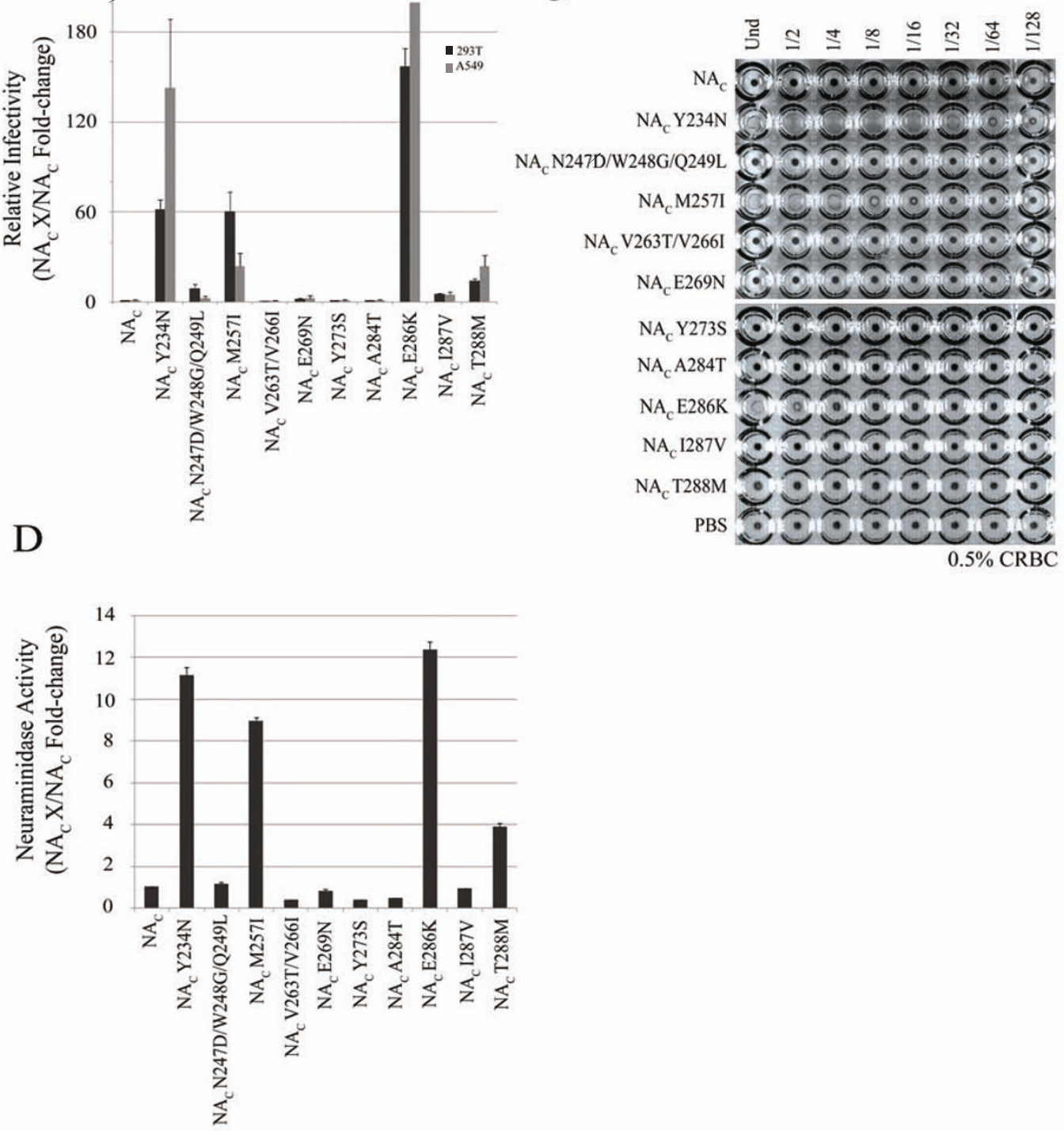

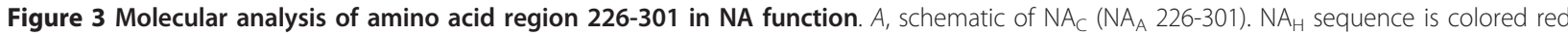
and $N A_{A}$ sequence is colored yellow. Single and combined substitutions generated in $N A_{C}\left(N A_{A} 226-301\right)$ are shaded. $B_{1}$, relative infectivity of 293T and A549 target cells challenged with pseudovirus produced in the presence of respective $N A_{C}\left(N A_{A}\right.$ 226-301) mutants. Luciferase activity is presented as fold-change. Experiments were performed in triplicates and repeated several times, and error bars indicate standard deviations. $C_{\text {, }}$ hemagglutination activity of $\mathrm{NA}_{C}\left(\mathrm{NA}_{\mathrm{A}}\right.$ 226-301) substitution panel. Pseudovirions were mixed with chicken red blood cells and HA titers recorded. $D$, neuraminidase activity of $N A_{C}\left(N A_{A}\right.$ 226-301) substitution mutants measured by the release of fluorogenic substrate 4-MUNANA. Experiments were performed in triplicates and repeated several times, and error bars indicate standard deviations. 
A

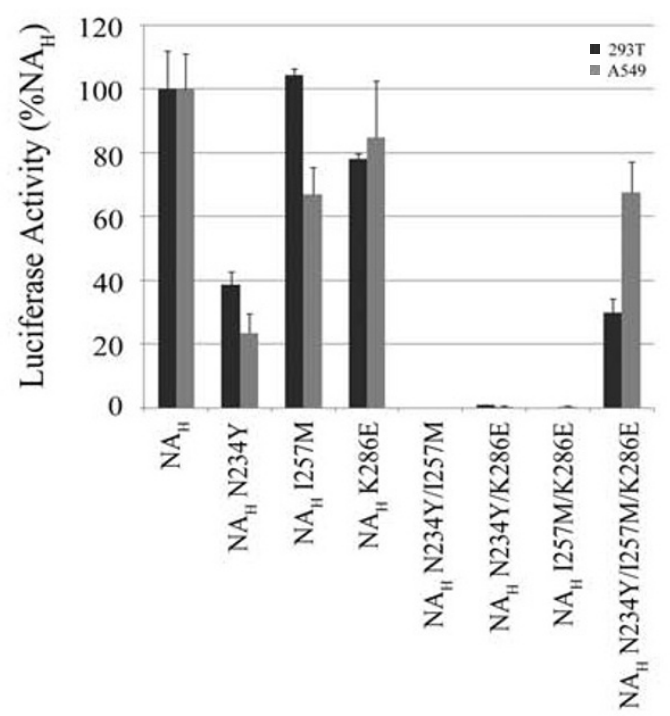

$\mathrm{C}$

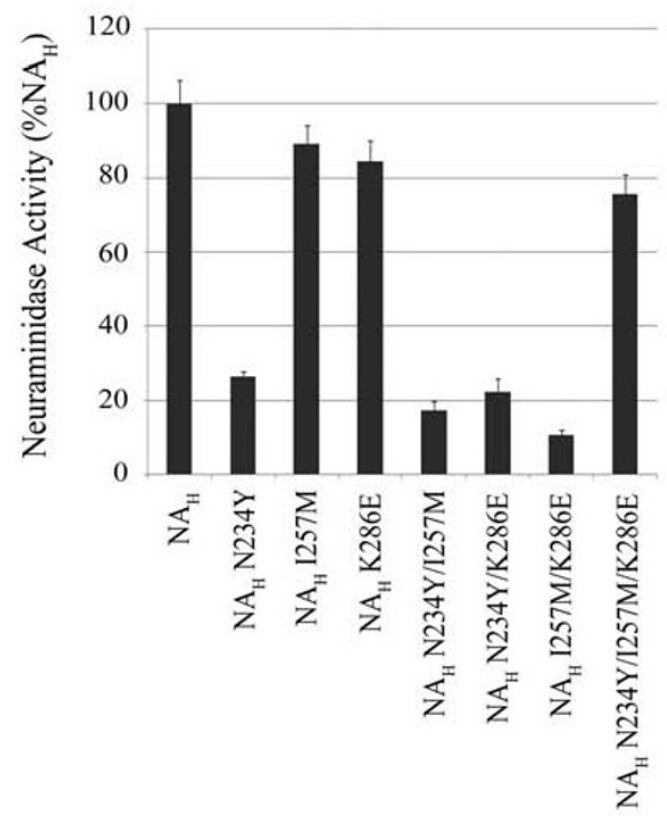

$\mathrm{B}$
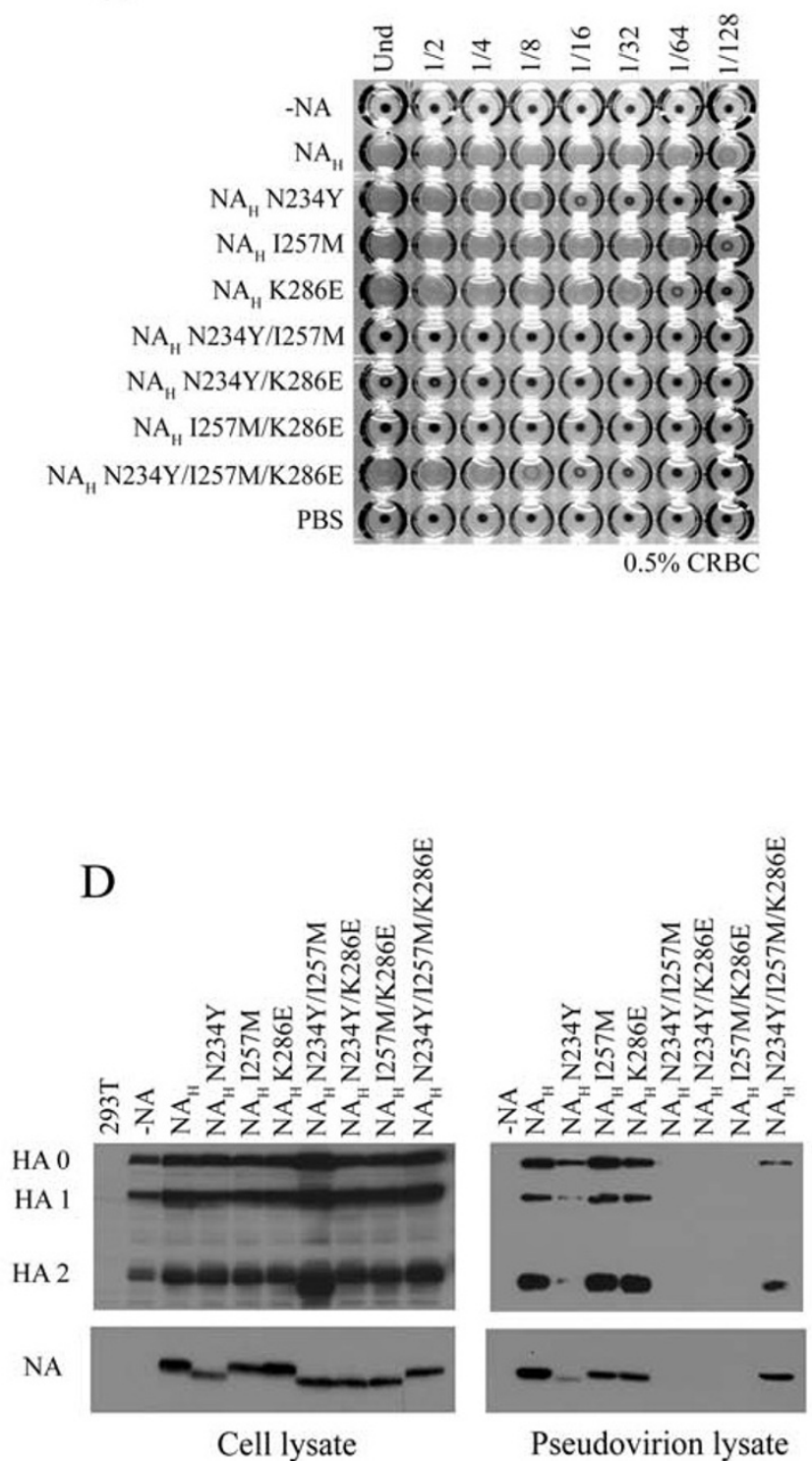

Pseudovirion lysate

Figure 4 Characterization of critical residues necessary for NA function. $A$, relative infectivites of pseudovirions produced in the presence of $\mathrm{NA}_{H}$ N234Y, $1257 \mathrm{M}$ and K286E single and combined substitution mutants (N2 numbering). Experiments were performed in triplicates and repeated several times, and error bars indicate standard deviations. $B$, hemagglutination activity of $N A_{H}$ substitution panel. $C$, neuraminidase activity of $N A_{H}$ substitutions measured by the release of fluorogenic substrate 4-MUNANA. Enzyme activity is presented as the fold-change of triplicate samples. Experiments were performed in triplicates and repeated several times, and error bars indicate standard deviations. D, western blot of HA and NA expression in 293T cell lysates and incorporation onto HIV particles. The HA precursor (HA0), and proteolytic subunits (HA1 and HA2) are detected in both cell and virus lysates. 
A

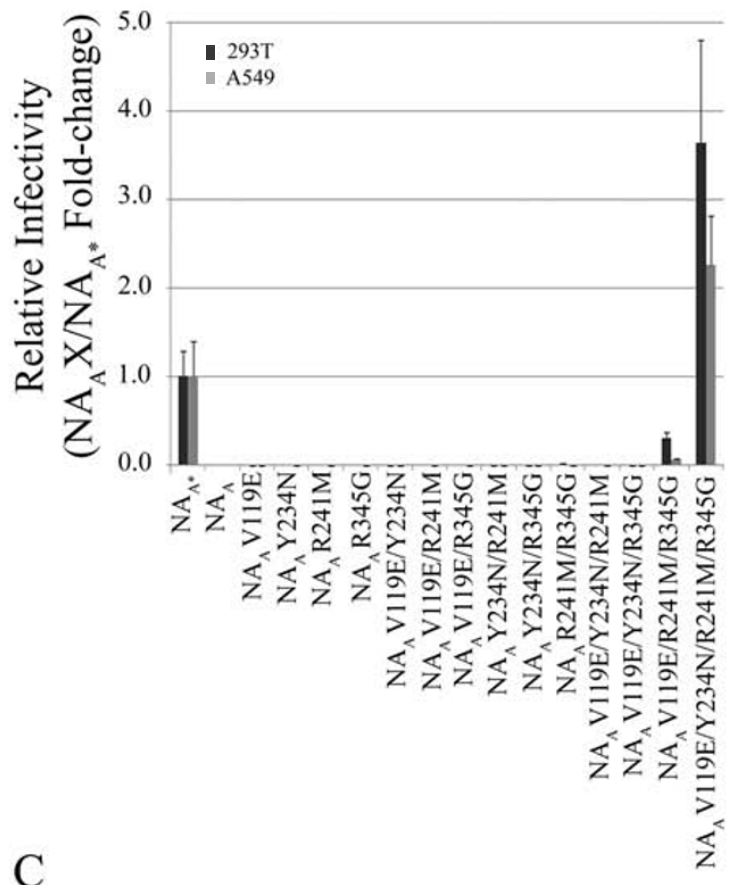

B

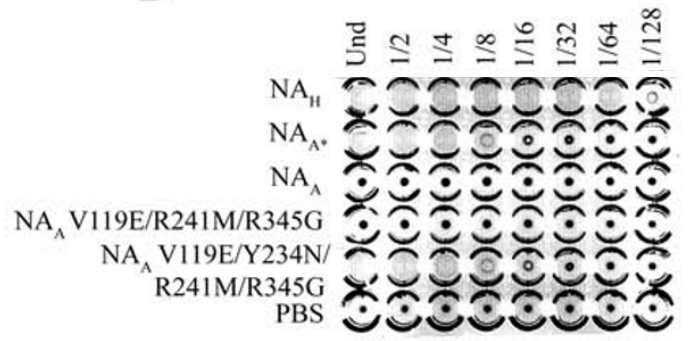

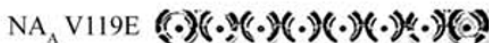

$\left.\mathrm{NA}_{A} \mathrm{Y} 234 \mathrm{~N}(\cdot)(\cdot)(\cdot)(\cdot)(\cdot)(\cdot)(\cdot)(\cdot)\right)$

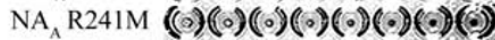

$\mathrm{NA}_{\mathrm{A}} \mathrm{R} 345 \mathrm{G}((\cdot)(\cdot)(\cdot)(\cdot)(\cdot)(\cdot)(\cdot)(\cdot)$

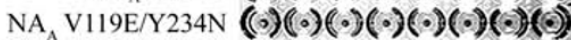

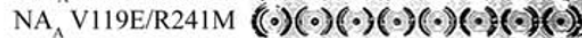

$\left.\mathrm{NA}_{\mathrm{A}} \mathrm{V} 119 \mathrm{E} / \mathrm{R} 345 \mathrm{G}(\cdot)(\cdot)(\cdot)(\cdot)(\cdot)(\cdot)(\cdot)(\cdot)\right)$

$\mathrm{NA}_{A} \mathrm{Y} 234 \mathrm{~N} / \mathrm{R} 241 \mathrm{M}(\cdot)(\cdot)(\cdot)(\cdot)(\cdot)(\cdot)(\cdot)(\cdot)$

NA Y234N/R345G $(\cdot)(\cdot)(\cdot)(\cdot)(\cdot)(\cdot)(\cdot)(\cdot)$

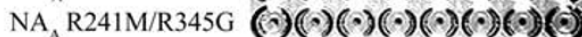

NA V119E/Y234N/R241M $(\cdot)(\cdot)(\cdot)(\cdot)(\cdot)(\cdot)(\cdot)(0)$

$\mathrm{NA}_{A} \mathrm{~V} 119 \mathrm{E} / \mathrm{Y} 234 \mathrm{~N} / \mathrm{R} 345 \mathrm{G}(\cdot)(\cdot *)(\cdot)(\cdot)(\cdot)(\cdot) \cdot(\cdot) \cdot(\cdot)$

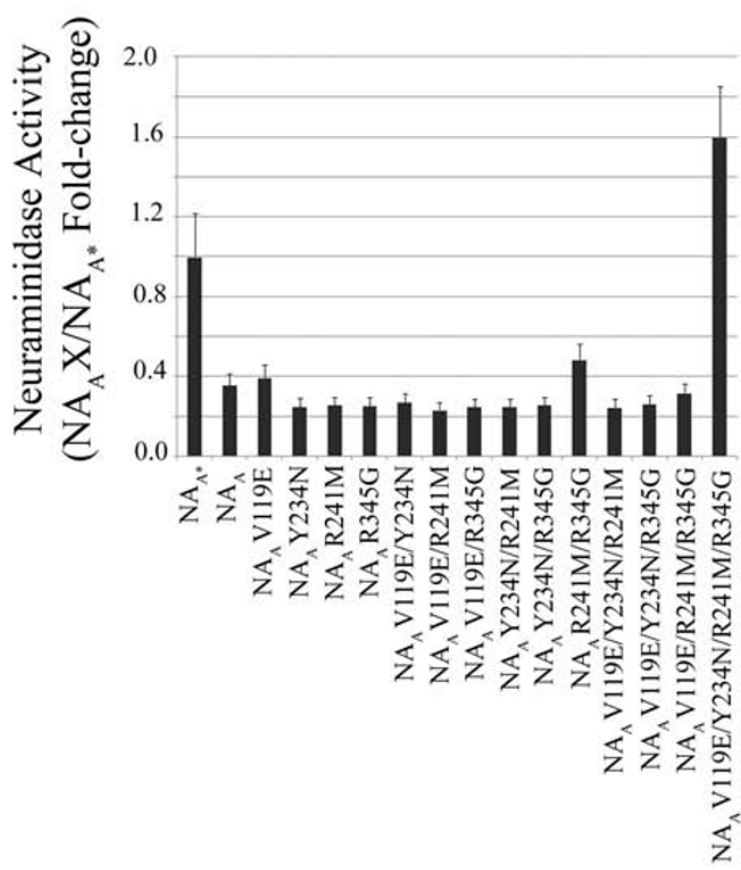

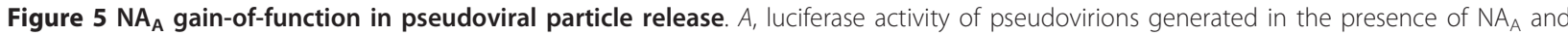
$N A_{A}$ mutants containing single or combined substitutions V119E, Y234N, R241M and R345G (N2 numbering). Experiments were performed in triplicates and repeated several times, and error bars indicate standard deviations. $B$, hemagglutination activity of $N A_{A}$ substitution panel. $C$, neuraminidase activity of $\mathrm{NA}_{C}$ (Av 226-301) substitution mutants measured by the release of fluorogenic substrate 4-MUNANA. Experiments were performed in triplicates and repeated several times, and error bars indicate standard deviations. 


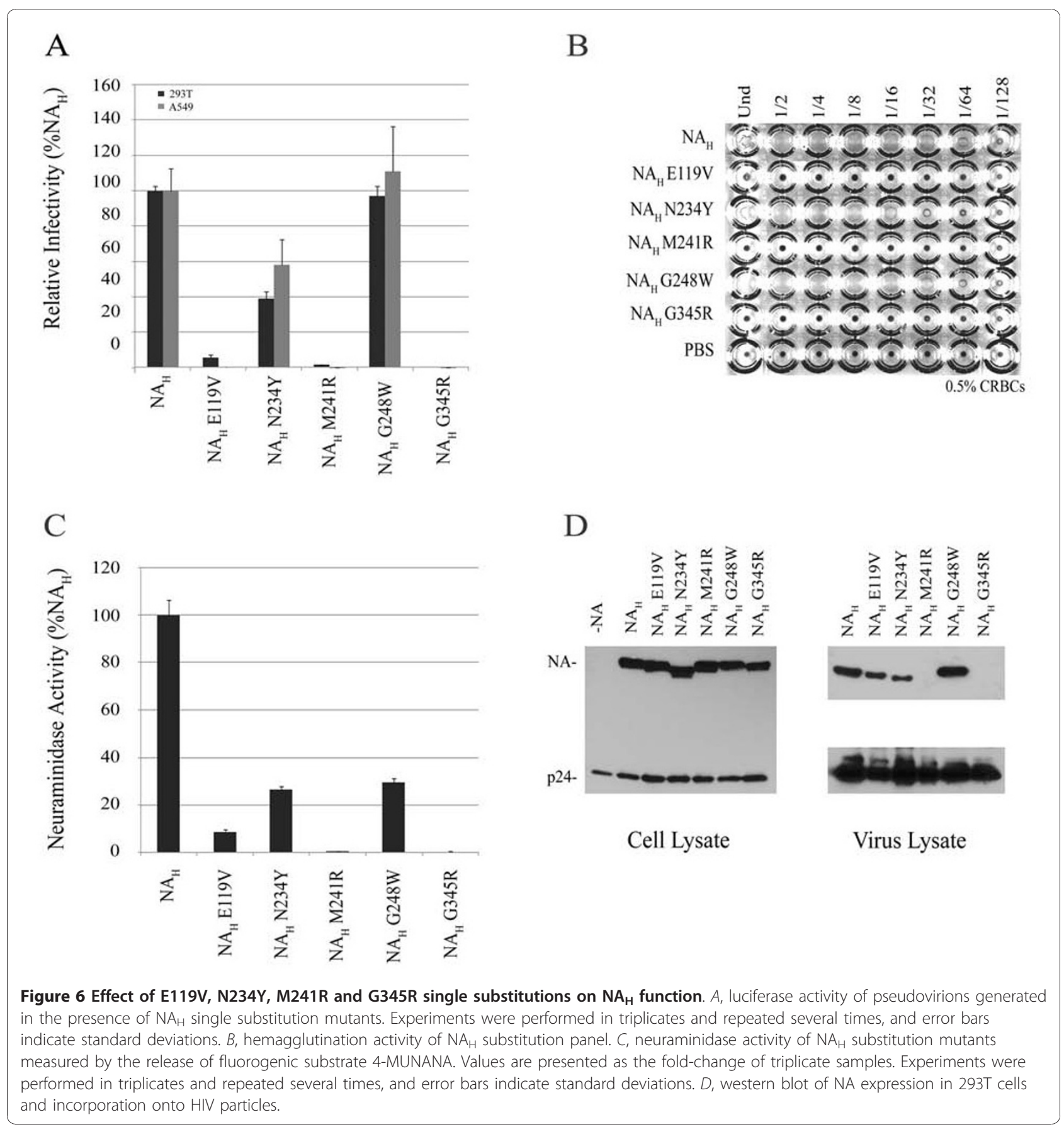

The asparagine residue found at position 234 is surface exposed (see Figure 7) and is part of a conserved motif (Asn-X-Ser/Thr) that denotes an N-linked glycosylation site. NAs containing N234Y substitution displayed a mobility shift on an SDS-PAGE gel suggesting that elimination of this glycosylation site on NA resulted in the loss of the carbohydrate modification. Interestingly, a similar mobility shift was also observed with the $\mathrm{NA}_{\mathrm{H}} \mathrm{I} 257 \mathrm{M} / \mathrm{K} 286 \mathrm{E}$ double substitution mutant that retained N234. We speculate that this was likely due to a misfolded NA which altered or masked the glycosylation site and prevented carbohydrate attachment. Glycosylation of N234 may be important for NA activity required to mediate the release of HA-containing HIV particles; however, like all the NA mutants, the mutation does not affect protein expression on the cellular surface.

It is interesting to point out that the individual substitutions N234, I257 or K286 in $\mathrm{NA}_{\mathrm{H}}$ impaired NA function, but a more striking defect was observed when any two substitutions were combined (see Figure 4). All 


\section{A}

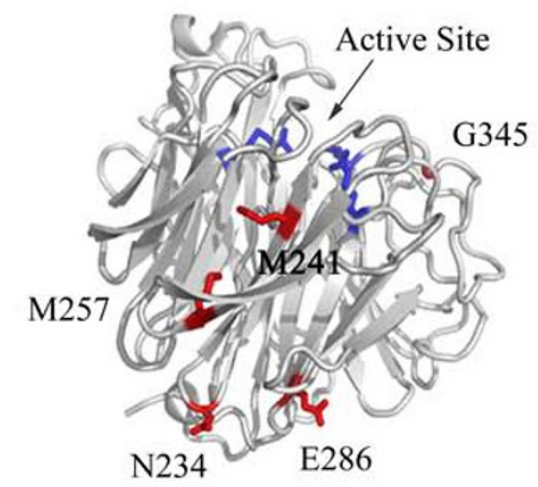

$\mathrm{C}$

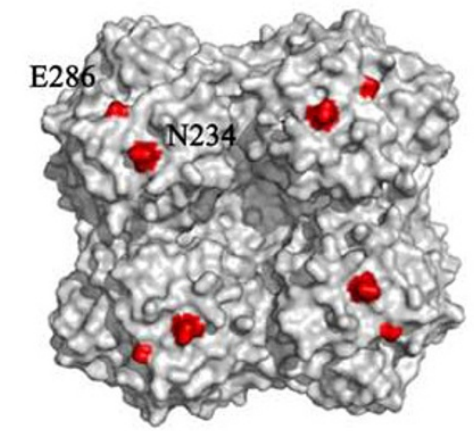

B

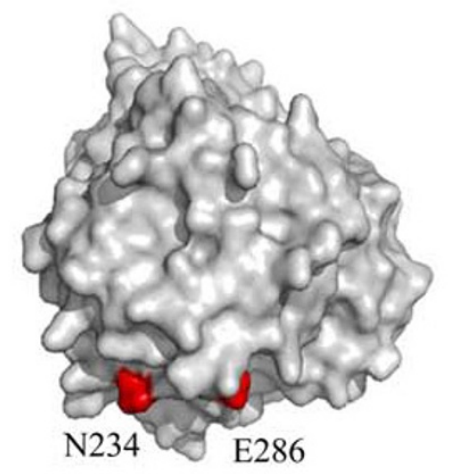

$\mathrm{D}$

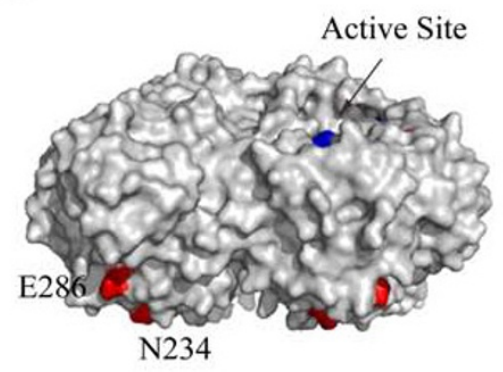

Figure 7 Projection of critical NA residues onto the tertiary structure. A, NA monomer ribbon diagram. Tri-arginyl residues (R118, R292 and R371) are labeled blue for reference of the enzyme active site. Residue substitution sites (N234, M241, M257, E286, and G345) are labeled red. B, NA monomer surface representation. N234 and E286 are shown in red. C, NA tetramer surface representation. View is looking up from the virion surface at the underside of the globular head. N234 and E286 are shown in red. D, side profile view of NA tetramer surface representation, parallel to the viral membrane. N234 and E286 are labeled red and the active site is labeled blue. The NA structures are displayed using PyMOL published by DeLano Scientific. PDB ID: 2HTY[34,35].

three double mutants were detectable in the cell lysates, with a faster migrating position on SDS-PAGE, but these mutants were not detected on the cell surface explaining their absence on the HIV pseudovirions. However, the triple mutant behaved more like $\mathrm{NA}_{\mathrm{H}}$, with greatly restored NA activities. Further analysis of the roles of these residues may provide insights on NA structure and function. Since many of these residues are clustered on the underside of the large globular head when projected onto the three-dimensional structure of avian influenza H5N1 NA. We speculate that this region may be a unique target site on NA for the design of novel inhibitors.

Currently, NA inhibitor oseltamivir carboxylate (Tamiflu) is the best available drug for influenza treatment. Its efficacy, however, is limited due its high propensity to select for drug-resistant variants, which is becoming an increasing problem with seasonal influenza strains. Thus, it is important to continue efforts for the design and development of more potent and efficacious drugs to treat influenza infection. The region in which residues 234, 286-both of which are surface exposed and lie adjacent to each other on the underside of the ectodomainand internal residue 257 may offer a unique opportunity to explore a new target region on NA, particularly since we have demonstrated this region's importance in NA function. We believe that these assays can be adapted for characterizing the NA function of 1918 pandemic influenza virus to alleviate safety concerns. Of interest, residue 234 of H1N1 NA has been recently demonstrated to be a "permissible" secondary mutation site which may allow the virus to compensate for the reduced fitness of 
oseltamivir resistance phenotype of H274Y [29], underlying the importance of the residue 234 identified as being important in NA function.

\section{Methods \\ Cell lines}

Human 293T cells were maintained in Dulbecco's modified Eagle's Medium (DMEM; HyClone) supplemented with $10 \%$ fetal bovine serum (FBS; HyClone), $100 \mu \mathrm{g} / \mathrm{ml}$ of streptomycin and 100 units of penicillin (Invitrogen). Human lung epithelial A549 cells were grown in Roswell Park Memorial Institute medium (RPMI; Invitrogen) supplemented with $10 \%$ fetal bovine serum (FBS; HyClone), $100 \mu \mathrm{g} / \mathrm{ml}$ of streptomycin, 100 units of penicillin (Invitrogen), 1\% Na-pyruvate and 1\% 1 M HEPES.

\section{Constructs and reagents}

The HA gene is from highly pathogenic avian influenza A/Goose/Qinghai/59/2005 (H5N1) virus isolated from infected migratory waterfowl found in Lake Qinghaihu, Qinghai Province, in western China [30]. NA cDNA from the mouse-adapted A/Puerto Rico/8/1934 (H1N1; PR8) influenza virus strain was kindly provided by John Olsen, University of North Carolina [31]. The mRNA and plasmid borne NA gene were derived from highly pathogenic avian influenza A/chicken/Henan/12/2004 (H5N1) virus. The HIV-1 vector pNL4-3.Luc. $\mathrm{R}^{-} \mathrm{E}^{-}$and mouse monoclonal anti-p24 HIV antibody were obtained through the NIH AIDS Research and Reference Reagent program (Germantown, MD). Polyclonal anti-HA (H5) NR163 was obtained from the Biodefense and Emerging Infections Research Resources Repository (Manassas, VA).

NA chimeric constructs were created by a two-step PCR technique with custom designed, overlapping primers. The amplified fragments were cloned into pEF6/ V5-His-TOPO vector (Invitrogen) using KpnI and NotI restriction enzymes and the sequence was confirmed by DNA sequencing. Influenza virus mRNA from A/ chicken/Henan/12/2004 (H5N1) was reverse transcribed into cDNA using primer set (5'to 3'acacggagcaaaagcagg and acgcggagtagaaacaagg) [32]. The NA cDNA was amplified using segment-specific primers and the resulting PCR product inserted into pEF6/V5-His-TOPO vector (Invitrogen). Site-directed mutagenesis of the NA genes was performed using the Strategene QuickChange mutagenesis kit following the supplier's protocol with custom designed primers carrying the designated mutation. All NA mutants were confirmed by DNA sequencing of the full-length NA gene.

\section{Production of pseudovirions and infection assay}

Influenza pseudovirions were produced in $293 \mathrm{~T}$ cells using a polyethylenimine (PEI)-based transfection protocol. Plasmid DNAs were co-transfected into 293T cells and after $48 \mathrm{~h}$ post-transfection, culture supernatants were collected, filtered through a $0.45 \mu \mathrm{m}$-pore size filter (Nalgene) and used to directly infect 293T and A549 target cells. Empty vector was used in place of omitted plasmids where appropriate. Relative infectivity was determined $48 \mathrm{~h}$ post-infection by measuring luciferase activity of the reporter gene using an FB12 luminometer at 10 second intervals (Berthold detection system). Each sample was done in triplicate and the experiments repeated at least three times. For NA treatment, a commercial neuraminidase (Clostridium perfringens; New England Biolabs) was added to producer cells at $26 \mathrm{~h}$ and $46 \mathrm{~h}$ post-transfection at a concentration of 5 units $/ \mathrm{ml}$.

\section{Hemagglutination assay}

Producer cell culture supernatants were harvested $48 \mathrm{~h}$ post-transfection, filter-sterilized and concentrated over a 30\% Sucrose-NTE cushion consisting of $100 \mathrm{mM}$ $\mathrm{NaCl}, 10 \mathrm{mM}$ Tris (pH 7.4), and $1 \mathrm{mM}$ EDTA by centrifugation at 55,000 rpm for $2 \mathrm{~h}$ in a SW55Ti rotor at $4^{\circ}$ C. Pseudovirion pellets were resuspended in $50 \mu \mathrm{l}$ of Tris-buffer containing $50 \mathrm{mM}$ Tris- $\mathrm{HCl}(\mathrm{pH} 7.5), 150$ $\mathrm{mM} \mathrm{NaCl}$, and $5 \mathrm{mM}$ EDTA. Twofold serial dilutions were mixed with an equal volume of $0.5 \%$ chicken erythrocyte suspension (CRBCs; Lampire Biological Laboratories) and incubated in a U-bottomed 96-well plate at $4^{\circ} \mathrm{C}$. HA titers were recorded after $1 \mathrm{~h}$. Hemagglutination assay experiments were repeated at least three times.

\section{Neuraminidase enzyme assay}

A standard fluorometric enzyme assay developed by Potier et al. was adapted to measure NA activity [33]. Producer cell lysates transfected with representative NA constructs were added to NA fluorogenic substrate 2'(4-methylumbelliferyl- $\mathrm{N}$-acetylneuraminic acid (4MUNANA; Sigma) to a final concentration of $100 \mu \mathrm{M}$. The reactions were carried out in $50 \mu \mathrm{l}$ of $33 \mathrm{mM}$ MES ( $\mathrm{pH}$ 6.5) containing $4 \mathrm{mM} \mathrm{CaCl}_{2}$ in 96 -well black Optiplates (BD Biosciences) and incubated in a $37^{\circ} \mathrm{C}$ water bath for $1 \mathrm{~h}$. The reactions were terminated by adding $150 \mu \mathrm{l}$ stop solution containing $0.5 \mathrm{M} \mathrm{NaOH}(\mathrm{pH} 10.7)$ and $25 \%$ ethanol. The fluorescence of released 4-methylumbelliferone was measured using a Labsystems Fluoroskan II spectrophotometer (PerkinElmer). The excitation wavelength was set at $355 \mathrm{~nm}$, and the emission wavelength was set at $460 \mathrm{~nm}$. Samples were done in triplicate and the experiments repeated at least three times.

\section{Immunoblot analysis}

NA genes modified to express a C-terminal HA-epitope tag were used to analyze NA protein expression in the producer cell lysates and NA incorporation onto HIV 
particles. 293T cells were transfected with representative NA plasmids and $48 \mathrm{~h}$ post-transfection the cells were washed in ice-cold PBS and then lysed in $0.2 \mathrm{ml}$ of Triton X-100 lysis buffer containing $50 \mathrm{mM}$ Tris- $\mathrm{HCl}(\mathrm{pH}$ 7.5), $150 \mathrm{mM} \mathrm{NaCl}, 5 \mathrm{mM}$ EDTA, $1 \%$ Triton-X, and a protease inhibitor cocktail. The cell culture supernatants were layered over a $20 \%$ sucrose cushion and centrifuged at 55,000 rpm for $45 \mathrm{~min}$ in a SW55Ti rotor at $16^{\circ} \mathrm{C}$. The pseudovirion pellets were lysed in $1 \%$ Triton $\mathrm{X}-100$ lysis buffer, samples subjected to SDS-PAGE and then transferred to a PVDF membrane. NA was detected with monoclonal anti-HA antibody (Sigma) and HIV core with monoclonal anti-p24 antibody. The membrane was then probed with peroxidase-conjugated goat anti-mouse secondary antibody and the protein bands visualized by chemiluminescence (Pierce).

\section{NA cellular surface expression}

Producer cells were transfected with representative NA plasmids and $48 \mathrm{~h}$ post-transfection the cells were washed and then released in PBS (pH8.0) containing 0.5 mM EDTA. Cell surface proteins were biotinylated for $30 \mathrm{~min}$ at $4^{\circ} \mathrm{C}$ using EZ-Link ${ }^{\mathrm{TM}}$ Sulfo-NHS-LC-Biotin reagent (Thermo Fischer Scientific). Cells were washed twice with ice-cold PBS ( $\mathrm{pH}$ 8.0) containing $100 \mathrm{mM}$ glycine, once with ice-cold PBS ( $\mathrm{pH} 8.0$ ), and then lysed in Triton-X 100 lysis buffer containing a protease inhibitor cocktail. Biotinylated surface proteins were separated from cell lysates using NeutrAvidin Agarose Resin (Thermo Fisher Scientific) by incubating mixtures overnight at $4{ }^{\circ} \mathrm{C}$. Agarose beads were washed twice with PBS ( $\mathrm{pH}$ 8.0) and resuspended in PBS. Samples were subjected to SDS-PAGE analysis and NA proteins were detected following the immunoblot protocol described above.

\section{Acknowledgements}

We thank Jennifer LaMora for technical assistance, Dr. John Olsen at the University of North Carolina at Chapel Hill for providing cDNA from the mouse-adapted A/Puerto Rico/8/1934 (H1N1) influenza virus strain. We thank Dr. James Cook at the University of Illinois at Chicago for providing A549 cells.

The laboratory research was supported by National Institutes of Health grant Al 059570 (to L. R.).

\footnotetext{
Author details

${ }^{1}$ Department of Microbiology and Immunology, University of Illinois at Chicago, Chicago, IL 60612, USA. ${ }^{2}$ Institute of Materia Medica, Peking Union Medical College and Chinese Academy of Medical Sciences, Beijing 100052, China. ${ }^{3}$ College of Life Sciences, Nankai University, Tianjin 300071, China. ${ }^{4}$ State Key Laboratory of Molecular Virology and Genetic Engineering, Institute of Pathogen Biology, Chinese Academy of Medical Sciences, Beijing 100052, China.
}

\section{Authors' contributions}

$J R T, Y G, K C, J Y, J W, Y C$, and LR participated in the study design, JRT, YG, KC, $J Y$ performed the experiments, and all authors participated in manuscript writing and revising. All authors read and approved the final manuscript.

\section{Competing interests}

The authors declare that they have no competing interests.

Received: 10 November 2010 Accepted: 13 January 2011

Published: 13 January 2011

\section{References}

1. Subbarao K, Klimov A, Katz J, Regnery H, Lim W, et al: Characterization of an avian influenza $A(H 5 N 1)$ virus isolated from a child with a fatal respiratory illness. Science 1998, 279:393-396.

2. Lin YP, Shaw M, Gregory V, Cameron K, Lim W, et al: Avian-to-human transmission of H9N2 subtype influenza $A$ viruses: relationship between H9N2 and H5N1 human isolates. Proc Natl Acad Sci USA 2000, 97:9654-9658.

3. Koopmans M, Wilbrink B, Conyn M, Natrop $G$, van der Nat $H$, et al: Transmission of H7N7 avian influenza $A$ virus to human beings during a large outbreak in commercial poultry farms in the Netherlands. Lancet 2004, 363:587-593.

4. Palese P: Influenza: old and new threats. Nat Med 2004, 10:582-87.

5. Horimoto T, Kawaoka Y: Influenza: lessons from past pandemics, warnings from current incidents. Nat Rev Microbiol 2005, 3:591-600.

6. Russell CJ, Webster RG: The genesis of a pandemic influenza virus. Cell 2005, 123:368-371

7. Fauci AS: Emerging and re-emerging infectious diseases: influenza as a prototype of the host-pathogen balancing act. Cell 2006, 124:665-670.

8. Webster RG, Govorkova EA: H5N1 influenza-continuing evolution and spread. N Engl J Med 2006, 355:2174-2177.

9. Bour S, Perrin C, Strebel K: Cell surface CD4 inhibits HIV-1 particle release by interfering with Vpu activity. J Biol Chem 1999, 274:33800-33806.

10. Martin-Serrano J, Zang T, Bieniasz PD: HIV-1 and Ebola virus encode small peptide motifs that recruit Tsg101 to sites of particle assembly to facilitate egress. Nat Med 2001, 7:1313-1319.

11. Matrosovich MN, Matrosovich TY, Gray T, Roberts NA, Klenk HD: Human and avian influenza viruses target different cell types in cultures of human airway epithelium. Proc Natl Acad Sci USA 2004, 101:4620-4624.

12. Huang IC, Li W, Sui J, Marasco W, Choe H, et al: Influenza A virus neuraminidase limits viral superinfection. J Virol 2008, 82:4834-4843.

13. Goto $H$, Kawaoka Y: A novel mechanism for the acquisition of virulence by a human influenza A virus. Proc Natl Acad Sci USA 1998, 95:10224-10228.

14. Lazarowitz SG, Goldberg AR, Choppin PW: Proteolytic cleavage by plasmin of the HA polypeptide of influenza virus: host cell activation of serum plasminogen. Virology 1973, 56:172-180

15. Chaipan C, Kobasa D, Bertram S, Glowacka I, Steffen I, et al: Proteolytic activation of the 1918 influenza virus hemagglutinin. J Virol 2009, 83:3200-3211.

16. Mitnaul LJ, Matrosovich MN, Castrucci MR, Tuzikov AB, Bovin NV, et al: Balanced hemagglutinin and neuraminidase activities are critical for efficient replication of influenza A virus. J Virol 2000, 74:6015-6020.

17. Gubareva LV, Nedyalkova MS, Novikov DV, Murti KG, Hoffmann E, et al: A release-competent influenza $A$ virus mutant lacking the coding capacity for the neuraminidase active site. J Gen Virol 2002, 83:2683-2692.

18. Nedyalkova MS, Hayden FG, Webster RG, Gubareva LV: Accumulation of defective neuraminidase (NA) genes by influenza $A$ viruses in the presence of NA inhibitors as a marker of reduced dependence on NA. J Infect Dis 2002, 185:591-598.

19. Colman PM, Varghese JN, Laver WG: Structure of the catalytic and antigenic sites in influenza virus neuraminidase. Nature 1983, 303:41-44.

20. Hulse DJ, Webster RG, Russell RJ, Perez DR: Molecular determinants within the surface proteins involved in the pathogenicity of H5N1 influenza viruses in chickens. J Virol 2004, 78:9954-9964.

21. Li S, Schulman J, Itamura S, Palese P: Glycosylation of neuraminidase determines the neurovirulence of influenza A/WSN/33 virus. J Virol 1993, 67:6667-6673.

22. Matsuoka Y, Swayne DE, Thomas C, Rameix-Welti MA, Naffakh N, et al: Neuraminidase stalk length and additional glycosylation of the hemagglutinin influence the virulence of influenza H5N1 viruses for mice. J Virol 2009, 83:4704-4708. 
23. Zhou H, Yu Z, Hu Y, Tu J, Zou W, et al: The special neuraminidase stalkmotif responsible for increased virulence and pathogenesis of H5N1 influenza A virus. PLoS One 2009, 4:e6277.

24. Guo Y, Rumschlag-Booms E, Wang J, Xiao H, Yu J, et al: Analysis of hemagglutinin-mediated entry tropism of $\mathrm{H} 5 \mathrm{~N} 1$ avian influenza. Virol $J$ 2009, 6:39.

25. Gubareva LV, Webster RG, Hayden FG: Comparison of the activities of zanamivir, oseltamivir, and RWJ-270201 against clinical isolates of influenza virus and neuraminidase inhibitor-resistant variants. Antimicrob Agents Chemother 2001, 45:3403-3408.

26. Colman PM, Hoyne PA, Lawrence MC: Sequence and structure alignment of paramyxovirus hemagglutinin-neuraminidase with influenza virus neuraminidase. J Virol 1993, 67:2972-2980.

27. Lentz MR, Webster RG, Air GM: Site-directed mutation of the active site of influenza neuraminidase and implications for the catalytic mechanism. Biochemistry 1987, 26:5351-5358.

28. Burmeister WP, Ruigrok RW, Cusack S: The 2.2 A resolution crystal structure of influenza B neuraminidase and its complex with sialic acid. Embo J 1992, 11:49-56.

29. Bloom JD, Gong LI, Baltimore D: Permissive secondary mutations enable the evolution of influenza oseltamivir resistance. Science 2010, 328:1272-1275.

30. Liu J, Xiao H, Lei F, Zhu Q, Qin K, et al: Highly pathogenic H5N1 influenza virus infection in migratory birds. Science 2005, 309:1206.

31. McKay T, Patel M, Pickles RJ, Johnson LG, Olsen JC: Influenza M2 envelope protein augments avian influenza hemagglutinin pseudotyping of lentiviral vectors. Gene Ther 2006, 13:715-724.

32. Hoffmann E, Stech J, Guan Y, Webster RG, Perez DR: Universal primer set for the full-length amplification of all influenza A viruses. Arch Virol 2001, 146:2275-2289.

33. Potier M, Mameli L, Belisle M, Dallaire L, Melancon SB: Fluorometric assay of neuraminidase with a sodium (4-methylumbelliferyl-alpha-D-NacetyIneuraminate) substrate. Anal Biochem 1979, 94:287-296.

34. Berman HM, Bhat TN, Bourne PE, Feng Z, Gilliland G, et al: The Protein Data Bank and the challenge of structural genomics. Nat Struct Biol 2000, 7(Suppl):957-959.

35. Russell RJ, Haire LF, Stevens DJ, Collins PJ, Lin YP, et al: The structure of H5N1 avian influenza neuraminidase suggests new opportunities for drug design. Nature 2006, 443:45-49.

doi:10.1186/1743-422X-8-14

Cite this article as: Tisoncik et al: Identification of critical residues of influenza neuraminidase in viral particle release. Virology Journal 2011 8:14.

\section{Submit your next manuscript to BioMed Central and take full advantage of:}

- Convenient online submission

- Thorough peer review

- No space constraints or color figure charges

- Immediate publication on acceptance

- Inclusion in PubMed, CAS, Scopus and Google Scholar

- Research which is freely available for redistribution 